\title{
Nanotheranostics
}

2020; 4(4): 242-255. doi: $10.7150 /$ ntno.46408

Review

\section{Local delivery of insulin/IGF-1 for bone regeneration: carriers, strategies, and effects}

\author{
Xiaoxuan Zhang ${ }^{1,2^{*}}$, Helin Xing $3^{3^{*}}$, Feng Qi ${ }^{4}$, Hongchen Liu ${ }^{5^{\bowtie}}$, Lizeng Gao ${ }^{6^{\bowtie}}$ and Xing Wang ${ }^{1,2,5^{\bowtie}}$ \\ 1. Shanxi Medical University School and Hospital of Stomatology, Taiyuan 030001, China. \\ 2. Shanxi Province Key Laboratory of Oral Diseases Prevention and New Materials, Taiyuan 030001 China. \\ 3. Department of Prosthodontics, Beijing Stomatological Hospital and School of Stomatology, Capital Medical University, Beijing, 100050, China. \\ 4. Department of Mechanical and Aerospace Engineering, University of Missouri, Columbia, MO, USA. \\ 5. Institute of Stomatology \& Oral Maxilla Facial Key Laboratory, Chinese PLA General Hospital, 28 Fuxing Road, Beijing, 100853, China. \\ 6. CAS Engineering Laboratory for Nanozyme, Institute of Biophysics, Chinese Academy of Sciences, Beijing 100101, China. \\ *These authors contributed equally to this work. \\ $\triangle$ Corresponding authors: Xing Wang, Email: kqwx100@163.com, Tel: 13934224604; Lizeng Gao, Email: gaolizeng@ibp.ac.cn, Tel: 18752782532; Hongchen Liu,
} Email: liu-hc301@hotmail.com, Tel:13701144745.

(C) The author(s). This is an open access article distributed under the terms of the Creative Commons Attribution License (https://creativecommons.org/licenses/by/4.0/). See http:/ /ivyspring.com/terms for full terms and conditions.

Received: 2020.07.18; Accepted: 2020.08.21; Published: 2020.09.08

\begin{abstract}
Bone defects caused by trauma, tumor resection, congenital malformation and infection are still a major challenge for clinicians. Biomimetic bone materials have attracted more and more attention in science and industry. Insulin and insulin-like growth factor-1 (IGF-1) have been increasingly recognized as an inducible factor for osteogenesis and angiogenesis. Spatiotemporal release of insulin may serve as the promising strategy. Considering the successful application of nanoparticles in drug loading, various insulin delivery systems have been developed, including (poly (lactic-co-glycolic acid), PLGA), hydroxyapatite (HA), gelatin, chitosan, alginate, and ( $\gamma$-glutamic acid)/ $\beta$-tricalcium phosphate, $\gamma-P G A / \beta-T C P)$. Here, we have reviewed the progress on nanoparticles carrying insulin/IGF for bone regeneration. In addition, the key regulatory mechanism of insulin in bone regeneration is also summarized. The future application strategies and the challenges in bone regeneration are also discussed.
\end{abstract}

Key words: Nanoparticles, Insulin, Insulin-like growth factor, Bone regeneration, Angiogenesis, Osteogenesis

\section{Introduction}

According to the world health organization, over 500,000 bone grafting procedures with a cost greater than $\$ 2.5$ billion are performed annually in the United States [1]. However, considerable clinical problems on bone defect are so far unaddressed, with a remaining group of $10 \%$ to $20 \%$ of delayed or nonunion situations [2]. Owing to severe injury or congenital deformity, osteogenesis insufficiency, rheumatoid arthritis or osteoporosis, the long and limited selfhealing process of bone grafts cannot fully meet the requirements of timely bone regeneration sometimes [3-5].

Insulin is a hormone that regulates energy balance and plays an important role in bone metabolism. Skeletal abnormalities associated with type I diabetes can be restored after insulin therapy [6,
7]. Clinically, it is often observed that insulin deficiency is more likely to lead to fracture. In patients with type 2 diabetes mellitus, the use of insulin treatment significantly increased bone formation marker procollagen type $1 \mathrm{~N}$-terminal propeptide, which can reduce the risk of fracture $[8,9]$. In vivo studies have shown that insulin/IGF-1 can promote angiogenesis and provide nutrition for bone formation [10-12]. Insulin can effectively promote local skull bone formation by increasing the number of osteoblasts and osteoid surface area in the mouse skull [13], and can regulate the activity of osteoclasts [14]. In recent years, studies have found that IGF-1 can also affect the growth and development of osteoblasts, accelerating bone regeneration [15]. 


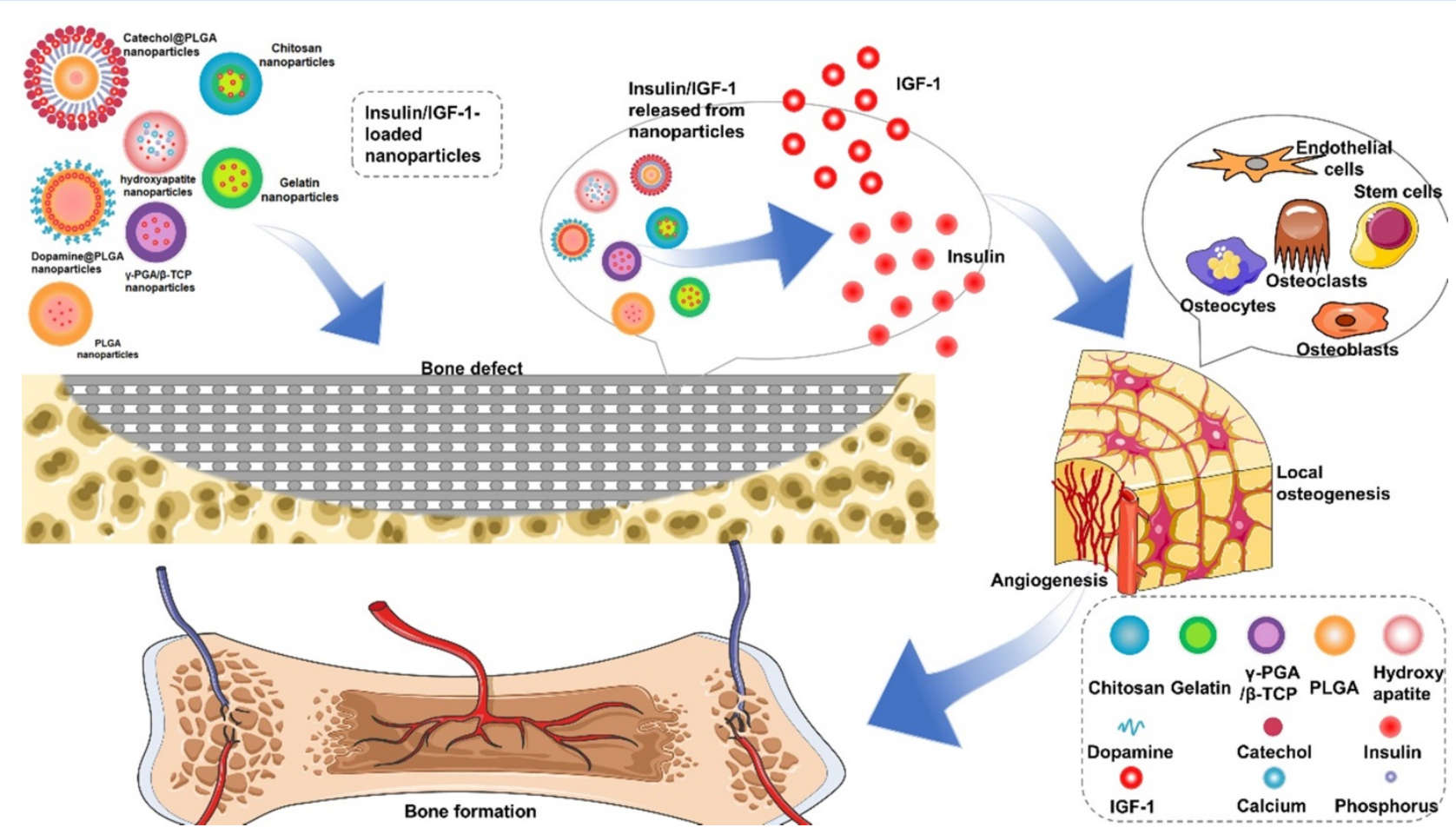

Figure 1. Summarization of strategies for insulin delivery for bone regeneration. Various nanoparticles-based delivery systems have been developed to improve the positive influence of insulin/IGF-1 on osteogenesis and angiogenesis.

However, the application of insulin in nondiabetic clinical bone defects has not received much attention, which may be due to the short life of insulin and the side effects of too much insulin. For example, the half-life of free insulin is only 20-30 min [16, 17]. Encapsulated insulin in chitosan nanoparticles can enhance the absorption of insulin by stem cells and improve the hypoglycemic effect [18]. This paper reviews the key regulatory mechanism of insulin in bone regeneration and the characteristics of different insulin loaded nanoparticles, such as: (poly (lactic-coglycolic acid), PLGA), hydroxyapatite (HA), gelatin, chitosan, alginate, and ( $\gamma$-glutamic acid) $/ \beta$-tricalcium phosphate, $\gamma$-PGA $/ \beta$-TCP) (Figure 1). The application strategies in bone regeneration are emphasized and the challenges in the future are discussed.

\section{Potent role of insulin/IGF in bone regeneration}

Insulin is derived from pancreatic beta cells, regulating mammalian cell growth and systemic energy metabolism [19]. Insulin receptors (IR) are a transmembrane glycoprotein with tyrosine kinase activity. The binding of insulin with IR causes autophosphorylation of IR [20, 21], activating downstream phosphoinositide-3-kinase (PI3-K)/Akt and mitogen activated protein kinase (MAPK) pathways, which affect the differentiation, energy metabolism and activity of osteocytes $[22,23]$. Within a concentration range, insulin exposure could increase bone synthesis markers, including glucose uptake, alkaline phosphatase (ALP) production and collagen synthesis. Osteoblasts without IR have declined osteogenic differentiation, and reduced levels of alkaline phosphatase and runt-related transcription factor 2 (Runx2) [20]. IGF is a group of growthpromoting polypeptide substances, whose secretory cells are widely distributed. IGF-1 has a molecular structure similar to insulin and possess cross-receptor to activate the downstream pathway, and IGF-1 can also bind IR and specifically activate insulin receptor substrate (IRS), a downstream insulin receptor substrate [24, 25].

\section{Insulin/IGF-1 promote osteogenesis}

Bone homeostasis is a dynamic balance that relies on tight interactions between osteoblasts and osteoclasts. IR exists in osteoblasts and osteoclasts, while IRS only exists in osteoblasts. IRS is a key factor in signal transduction of insulin and IGF-1 (Figure 2A). It has a docking effect with Src homology 2 signal molecules in cells, transferring the signal through Src homology 3 to Son of Sevenless, phosphorylating downstream Ras molecules, thereby activating the extracellular signal-related kinases (ERK1/2) pathway and regulating the growth, proliferation, and differentiation of osteoblasts [26, 27]. IRS tyrosine residues phosphorylation activates PI3-K [21], which means promotion of the transformation of phosphatidylinositol-4,5-bisphosphate to phosphatidylinositol-3,4,5-triphosphate. Phosphatidylinositol- 
3,4,5-triphosphate activates downstream AKT and then regulates the proliferation, survival and energy metabolism of osteoblasts through mammalian target of rapamycin, BCL-2-antagonist of cell death, forkhead box O1, and other pathways [28, 29]. IRS in osteoblasts can regulate the generation of receptor activator of nuclear factor-kappa B ligand (RANKL), thereby regulating the differentiation of osteoclasts [23]. Osteoblasts without insulin receptor substrate 1 cannot generate receptor activator of NF-kappaB ligand/osteoclast differentiation factor, which is critical for osteoclast development. The insulin receptor-deficient mice had been proved to show reduced bone resorption by osteoclasts, but the bone mass of these mice is still decreased, indicating that the inhibition of bone formation is stronger than that of bone resorption [19].

During bone regeneration, many transcripts must coordinate various factors to promote osteoblast differentiation, and Runx2 leads early stage differentiation [30]. Runx2 induces osteoblast differentiation and enhances migration by interacting with PI3K-Akt signaling [31]. Insulin signaling in osteoblasts plays a role by promoting the carboxylation of osteocalcin [19]. Osteoblast insulin receptor (IR) signaling controls osteoblast development and osteocalcin expression by inhibiting the Runx2 inhibitor Twist2 [20]. Rapamycin complex 1 (mTORC1) is a highly conserved regulator of cell growth and is one of the most integrated signaling nodes in all cells. mTORC1 promotes cell growth by responding to nutrients and growth factors. Insulin has been found to activate mTORC1 through the PI3K-Akt pathway [32].

\section{Insulin/IGF-1 promote angiogenesis}

In mammalian skeletal development, the formation of endochondral bone coincides with capillary invasion, suggesting a close relationship between osteogenesis and angiogenesis [33]. In the osteogenic microenvironment, osteoblasts, osteoclasts, osteocytes and endothelial progenitor cells are involved in bone regeneration [34,35].

Insulin and IGF-1 are important substance for promoting angiogenesis. Studies have shown that IR in endothelial cells promotes angiogenesis [36]. Insulin-like growth factor receptors is also found in the endothelium [37] (Figure 2B). IGF-1 binding to insulin-like growth factor receptors can activate downstream IRS and promote angiogenesis through the MAPK and PI3-K pathways [21, 38, 39]. IGF-1 can activate ERK to promote the formation of vascular endothelial cells, and the release of nitric oxide by the PI-3K/Akt pathway to reduce vascular inflammation $[40,41]$. Chemokine (C-X-C motif) ligand 9 (Cxcl9) as a direct anti-regulatory molecule of VEGF signal generated by osteoblasts, regulating bone angiogenesis and osteogenesis. mTORC1 activates the expression of Cxc19 by up-regulating STAT1 and increasing the binding of STAT1 to the Cxc19 promoter in osteoblasts [42], suggesting that insulin might promote angiogenesis via Cxc19.

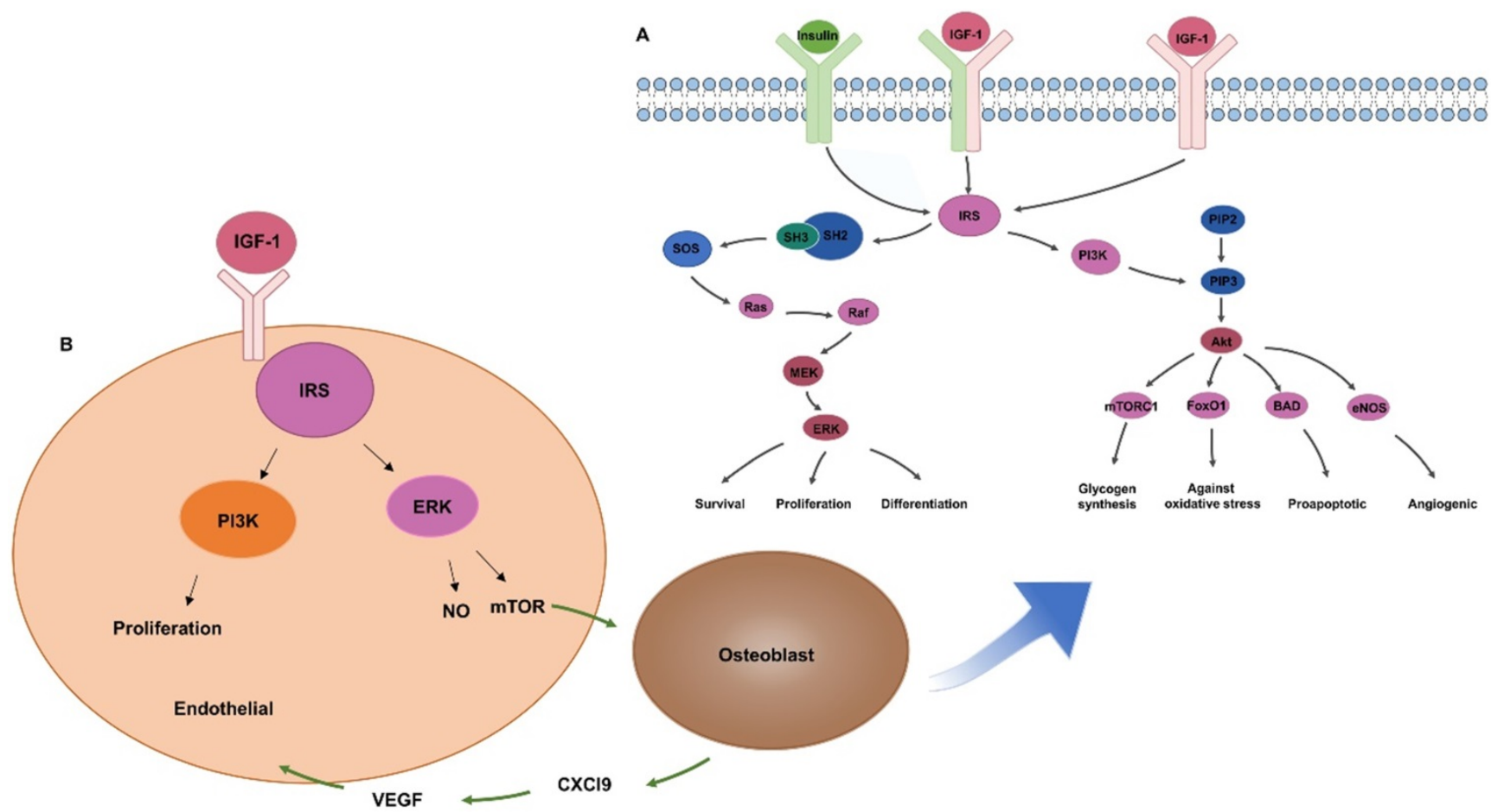

Figure 2. Insulin / IGF-1 regulates bone regeneration through MAPK / PI3-K signaling pathway. (A) Insulin / IGF-1 signal transduction in osteoblasts. (B) IGF-1 promotes angiogenesis by increasing endothelial cell proliferation. 
Table 1. Characteristics of insulin/IGF-1 nanoparticles

\begin{tabular}{|c|c|c|c|c|c|c|c|c|}
\hline Carrier & Synthesis Method & Components & Drug & LE/EE & Size & Release behaviour in vitro & Effect in bone regeneration & Ref \\
\hline PLGA & $\mathrm{W} / \mathrm{O} / \mathrm{W}$ system & DCM + PVA + PLGA & IGF-1 & $\mathrm{EE}=78.3 \%$ & - & $\begin{array}{l}\text { Initial burst release }(55.3 \%, 48 \\
\text { h); } \\
\text { More than } 85 \% \text { was released } \\
\text { within } 20 \text { days. }\end{array}$ & $\begin{array}{l}\text { Promote osseointegration of } \\
\text { dental implants. }\end{array}$ & [47] \\
\hline \multirow[t]{3}{*}{ PLGA } & $\begin{array}{l}(\mathrm{W} / \mathrm{O} / \mathrm{W}) \text { system } \\
\text { with SPG premix } \\
\text { membrane }\end{array}$ & DCM + PVA + PLGA & Insulin & $\begin{array}{l}\mathrm{LE}=5.4 \% \\
\mathrm{EE}=60.2 \%\end{array}$ & $121.2 \mathrm{~nm}$ & $\begin{array}{l}\text { Initial burst release }(51 \%, 24 \mathrm{~h}) \\
\text { followed drug release over } 5 \\
\text { days. }\end{array}$ & $\begin{array}{l}\text { Bone mineral density }(8 \\
\text { week): } 0.96 \pm 0.06 \mathrm{~g} / \mathrm{cm}^{3} \text {. }\end{array}$ & [48] \\
\hline & & & & $\begin{array}{l}\mathrm{LE}=28.27 \% \\
\mathrm{EE}=67.86 \%\end{array}$ & $1.61 \mu \mathrm{m}$ & $\begin{array}{l}\text { Initial burst release }(29 \%, 24 \\
\text { h); } \\
\text { Sustained release over } 30 \text { days. }\end{array}$ & $\begin{array}{l}\text { Bone mineral density }(8 \\
\text { week): } 1.10 \pm 0.07 \mathrm{~g} / \mathrm{cm}^{3} \text {. }\end{array}$ & \\
\hline & & & & $\begin{array}{l}\mathrm{LE}=33.72 \% \\
\mathrm{EE}=93.29 \%\end{array}$ & $21.45 \mu \mathrm{m}$ & $\begin{array}{l}\text { Initial lower burst }(18 \%, 24 \mathrm{~h}) \text {; } \\
\text { within a long period up to } 2 \\
\text { weeks, the release rate was } \\
\text { slow, but then increased in the } \\
\text { second month. }\end{array}$ & $\begin{array}{l}\text { Bone mineral density }(8 \\
\text { week): } 0.86 \pm 0.07 \mathrm{~g} / \mathrm{cm}^{3} \text {. }\end{array}$ & \\
\hline HA & $\begin{array}{l}\text { Dropwise } \\
\text { aqueous }\end{array}$ & $\begin{array}{l}\mathrm{Ca}\left(\mathrm{NO}_{3}\right)_{2} / \mathrm{Sr}\left(\mathrm{NO}_{3}\right)_{2} / \\
\mathrm{Zn}\left(\mathrm{NO}_{3}\right)_{2}\end{array}$ & Insulin & - & $<210 \mu \mathrm{m}$ & - & $\begin{array}{l}\text { SrHA/insulin promoted } \\
\text { stem cell proliferation. }\end{array}$ & [66] \\
\hline $\begin{array}{l}\text { PLGA } \\
/ \mathrm{HA}\end{array}$ & $\begin{array}{l}\text { Copolymerization } \\
\text { method }\end{array}$ & $\begin{array}{l}\mathrm{HA}+\mathrm{PEG}-\mathrm{DM}+ \\
\mathrm{DCC}+\mathrm{DMAP}\end{array}$ & IGF-1 & $\mathrm{LE}=99 \%$ & $131.3 \mathrm{~nm}$ & $\begin{array}{l}\text { Initial burst release ( } 4 \mathrm{~g} \text { within } \\
24 \mathrm{~h}) \text {; } \\
\text { Sustained release within } 28 \\
\text { days. }\end{array}$ & $\begin{array}{l}\text { Increase proliferation of } \\
\text { ADSCs on Ti substrates. }\end{array}$ & [51] \\
\hline $\begin{array}{l}\text { PLGA } \\
/ \mathrm{HA}\end{array}$ & $\begin{array}{l}\mathrm{O} / \mathrm{W} \text { emulsion } \\
+\mathrm{pDA} \text { coating }\end{array}$ & $\begin{array}{l}\mathrm{HA}+\mathrm{DCM}+\mathrm{PLGA}+ \\
\mathrm{PVA}+\mathrm{DA}\end{array}$ & IGF-1 & - & $223.71 \mu \mathrm{m}$ & - & $\begin{array}{l}\text { Increase proliferation, } \\
\text { adhesion, and osteogenic } \\
\text { differentiation of ADSCs. }\end{array}$ & [55] \\
\hline Gelatin & $\mathrm{W} / \mathrm{W}$ emulsion & $\begin{array}{l}\text { PEG + Dex-GMA/ } \\
\text { gelatin }\end{array}$ & IGF-1 & $\mathrm{LE}=5 \%$ & $30 \mu \mathrm{m}$ & $\begin{array}{l}\text { Initial burst release: } 20.4 \pm 1 \% \text {, } \\
24 \text { h release: > } 28 \text { days. }\end{array}$ & $\begin{array}{l}\text { Enhance periodontal tissue } \\
\text { regeneration. }\end{array}$ & [69] \\
\hline Gelatin & Swell + crosslink & $\begin{array}{l}\text { OPF + Gelatin } \\
\text { microparticles }\end{array}$ & IGF-1 & & $50-100 \mu \mathrm{m}$ & $\begin{array}{l}\text { Initial burst release }(30 \%, 24 \\
\text { h); } \\
1 \% \text { each day: (days } 18-28) \text {. }\end{array}$ & $\begin{array}{l}\text { Improves the subchondral } \\
\text { bone morphology and the } \\
\text { interaction with the } \\
\text { surrounding chondral } \\
\text { tissue. }\end{array}$ & [70] \\
\hline Gelatin & Heating crosslink & $\begin{array}{l}\text { OPF + Gelatin + } \\
\text { Glutaraldehyde }\end{array}$ & IGF-1 & $\begin{array}{l}\text { Loading 100-200 ng: } \\
\mathrm{EE}=100 \%\end{array}$ & $50-100 \mu \mathrm{m}$ & $\begin{array}{l}\text { Initial burst release: }(22 \%, 24 \\
\text { h); } \\
\text { Cumulative release } 28 \text { day. }\end{array}$ & - & [95] \\
\hline \multirow[t]{2}{*}{ Chitosan } & $\begin{array}{l}\text { Emulsification } \\
\text { method }\end{array}$ & $\begin{array}{l}\text { Chitosan + Cottonseed } \\
\text { oil + TPP }\end{array}$ & IGF-1 & $70.02 \mathrm{ng}$ & $50-80 \mu \mathrm{m}$ & $3.31 \%(14 \mathrm{~d})$ & - & [74] \\
\hline & $\begin{array}{l}\text { Coacervation } \\
\text { method }\end{array}$ & $\begin{array}{l}\text { Acetic acid + Chitosan } \\
+\mathrm{TPP}\end{array}$ & IGF-1 & $168.7 \mathrm{ng}$ & $500-700 \mu \mathrm{m}$ & $30.68 \%(14 \mathrm{~d})$ & $\begin{array}{l}\text { Enhance pre-osteoblasts } \\
\text { proliferation/differentiation }\end{array}$ & \\
\hline Chitosan & $\mathrm{W} / \mathrm{O}$ emulsion & $\begin{array}{l}\text { Gelatin + Glyoxal + } \\
\text { Chitosan }\end{array}$ & IGF-1 & - & - & $\begin{array}{l}\text { Initial burst release: } 48 \%, 24 \text { h; } \\
\text { Sustained release } 7 \text { days. }\end{array}$ & $\begin{array}{l}\text { Increase ALP activity of } \\
\text { W-20-17 cells. }\end{array}$ & [75] \\
\hline Alginate & $\begin{array}{l}\text { Electrospraying } \\
\text { method }\end{array}$ & $\begin{array}{l}\text { Sodium alginate } \\
\text { chitosan flakes }\end{array}$ & IGF-1 & $\mathrm{EE}=40 \%$ & $296 \pm 18 \mu \mathrm{m}$ & $60 \%$ within $24 \mathrm{~h}$ & $\begin{array}{l}\text { Promote the proliferation } \\
\text { and differentiation of } \\
\text { cementoblasts. }\end{array}$ & [79] \\
\hline$\gamma$-PGA/ $\beta$-TCP & $\begin{array}{l}\text { Two-step } \\
\text { desolvation }\end{array}$ & $\gamma-\mathrm{PGA}+\beta-\mathrm{TCP}$ & IGF-1 & - & - & $52.86 \%(12 \mathrm{~d})$ & $\begin{array}{l}\text { Sequential release of BMP-2 } \\
\text { and IGF-1 significantly } \\
\text { promoted the proliferation } \\
\text { and differentiation of } \\
\text { MC3T3-E1 cells. }\end{array}$ & [85] \\
\hline
\end{tabular}

ADSCs: adipose-derived mesenchymal stem cells; ALP: alkaline phosphatase; BMP-2: bone morphogenetic protein 2; DA: dopamine; DCM: dichloromethane; DCC: 1,3-dicyclohexylcarbodiimide; Dex-GMA: dextran-glycidyl methacrylate; DMAP: 4-dimethylaminopyridine; HA: hydroxyapatite; IGF-1: insulin-like growth factor 1; LE/EE: loading efficiency/encapsulation efficiency; OPF: oligo(poly(ethylene glycol) fumarate); pDA: polydopamine; PEG: polyethylene glycol; PEG-DM: Poly(ethylene glycol) dimethyl ether; PLGA: poly (lactic-co-glycolic acid); PVA: polyvinyl alcohol; $\gamma$-PGA/ $\beta$-TCP: ( $\gamma$-glutamic acid)/ $\beta$-tricalcium phosphate; SPG: Shirasu porous glass; SrHA:

strontium substitution in HA; TPP: tripolyphosphate; W/O/W: water/oil/water.

In summary, vascularization and osteogenesis are important indicators of bone regeneration [43]. Insulin/IGF-1 have potent roles in promoting bone regeneration, and therapeutic delivery of the factors should be beneficial.

\section{Application of insulin/IGF-loaded particles in bone regeneration}

Nanoparticles is a promising strategy, which has been widely used to release drugs, maintain local concentration and improve bioavailability of insulin. Various nanoparticles loaded with insulin/IGF have been used for bone regeneration, such as those made of PLGA, HA, chitosan, gelatin, alginate, and $\gamma$-PGA/
$\beta$-TCP nanoparticles. The preparation method, particle size, loading efficiency, encapsulation efficiency, and release behavior of the insulin-loaded nanoparticles are introduced in next part, as shown in Table 1.

\section{PLGA}

In the 1970s, polymer particles were firstly applied involved in the field of biomedicine. Since 1997, the Food and Drug Administration and European medical institutions gradually approved the use of PLGA in drug delivery systems [44]. The degradation rate of PLGA is mainly dependent on the ratio of glycolic acid to lactic acid monomer [45]. To obtain more detailed information on accurate 
regulation of the release profile of insulin-loaded particles, three kinds of uniform-sized insulin microspheres were prepared using the solvent extraction, solvent evaporation and cosolvent methods, respectively [46]. It was found that insulin-loaded microspheres prepared by the solvent evaporation method exhibited a relatively steady release rate during the first four weeks, which significantly stimulated the osteogenic differentiation of the stem cells and peri-implant bone regeneration.

Wang et al. [47] assessed the IGF-1 PLGA microspheres on bone healing around implants in type II diabetic rats. The preparation of PLGA is usually done by $\mathrm{W} / \mathrm{O} / \mathrm{W}$ double emulsion solvent evaporation process, which can be completed at room temperature. The average diameter of PLGA microspheres was $1.2525 \pm 0.6436 \mu \mathrm{m}$. The surface is smooth. The encapsulation efficiency was $78.3 \%$. The initial burst release of the IGF-1 microspheres was $55.3 \%$ within 2 days, and more than $85 \%$ IGF-1 was released within 20 days. The efficacy of the drug-loaded microspheres was evaluated at 4 and 8 weeks, and the bone-implant contact percentage was found to be significantly increased in the microspheres group. In this study, the osteogenic effect was observed by suspending PLGA microspheres in the blood and then implanting the implants. The suspended PLGA microspheres may move before implanting the implants, resulting in uneven distribution. In addition, the size of nanoparticles also has a great influence on the release behaviour, but it has not been pointed out. Wang et al. [48] investigated the relationship between release kinetics of insulin and particle size of PLGA nanoparticles in bone regeneration. In this study, three kinds of insulin-loaded PLGA particles with narrow size distribution were prepared by Shirasu porous glass premixed membrane emulsification technology (Figure 3A). The release kinetics showed that the initial release rate of PLGA microspheres with particle size of $1.61 \pm 0.08 \mu \mathrm{m}$ was about $29 \%$ in the first day, and the remaining insulin ceased to release for 30 days, and accelerated bone defect healing in vivo, compared with those with sizes of $121.62 \mathrm{~nm}$ and $21.45 \mu \mathrm{m}$. Wang's experiment showed that PLGA has the best effect of releasing growth factor to promote osteogenesis at about $1 \mathrm{um}$, and in this study, A Shirasu Glass premixed membrane was specifically used to control the error to around 0.08 , so that the particle size uniformity was improved and the release stability of the nano-microsphere was increased. Moreover, smaller particle size error can increase the repeatability of the experiment and has more potential in large-scale production.

A
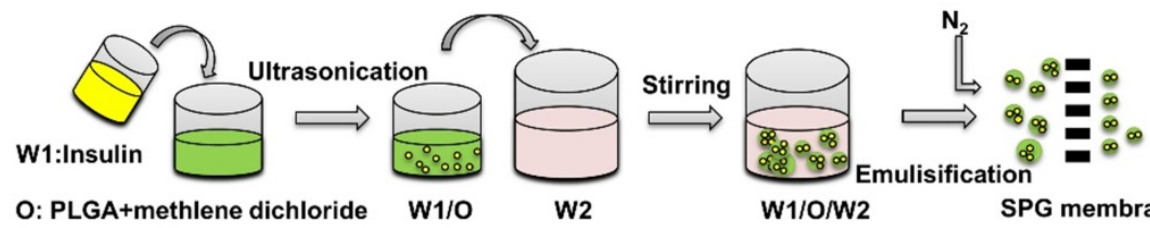

PLGA

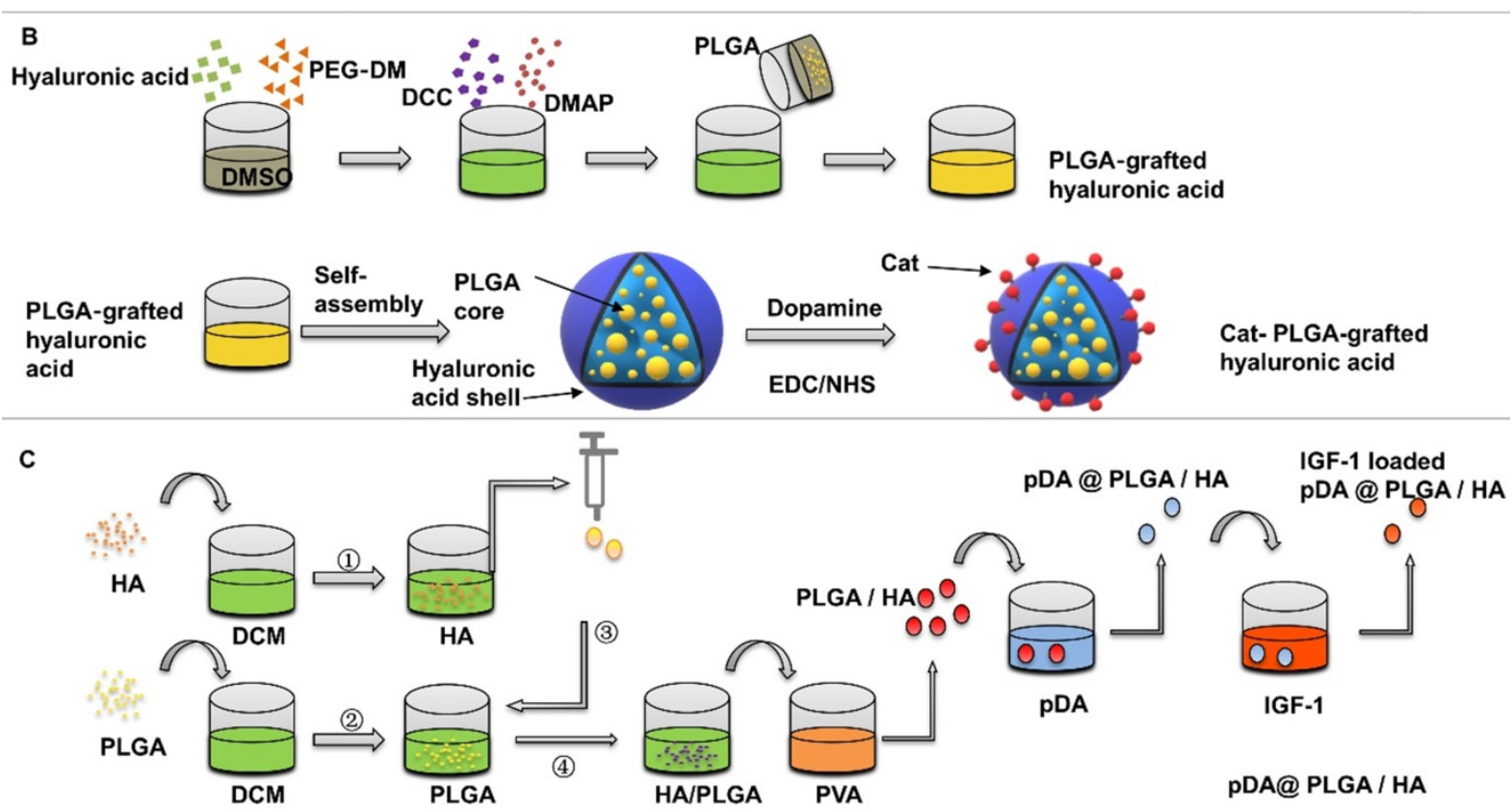

Figure 3. Preparation of insulin-loaded PLGA nanoparticles. (A) Insulin-loaded PLGA particles were prepared by Shirasu porous glass premixed membrane emulsification technology. Adapted with permission from [48], copyright 2017, American Chemical Society. (B) Preparation of Cat-HA-PLGA nanoparticles (C) pDA surface-modified PLGA/HA microspheres were prepared to deliver IGF-1. 


\section{Modification of PLGA}

Although PLGA nanoparticles are commonly used in bone tissue engineering for drug delivery, the hydrophobic nature of PLGA is not conducive to cell adhesion, which needs further optimization [49]. In order to optimize the effect of insulin-loaded PLGA on bone regeneration, many methods have been developed, including surface modification, and combination of PLGA to different materials [50].

Using surface modification is a common way to increase the protein adsorption of PLGA, Choi et al. [51] studied the PLGA-grafted hyaluronic acid nanoparticles with surface modified by catecholamine, which were synthesized by copolymerization method (Figure 3B). The catechol groups on the surface of nanoparticles increase the adhesion on the surface of titanium. The negative-charged hyaluronic acid shell can absorb positive-charged IGF-1, which improves the loading capacity of IGF-1. The release rate of growth factor is related to the loading concentration. The initial burst release is $2 \%$ at $200 \mathrm{ng}$ loading in the first 24 hours, and then reaches to $8 \%$ within 28 days slowly. In the same way, polydopamine (pDA) coating on the surface of particles can induce immobilization of some serum adhesives and adsorption of some cell types [52].

Recently, a multifunctional dopamine coating method has been developed, which only needs to immerse the substrate in alkaline dopamine solution [53]. Catechol groups of dopamine are oxidized in an alkaline environment to form pDA layer on organic and inorganic materials, such as polymers, metal and metal oxides [54]. pDA surface-modified PLGA/HA microcarriers with a diameter of $223.71 \pm 53.39 \mu \mathrm{m}$ were prepared by Gao et al. [55], then adiposederived mesenchymal stem cells were applied to detect the effect of pDA @ PLGA/HA/IGF-1 microcarriers on osteogenic differentiation (Figure 3C). It was found that the proliferation and the expression levels of Runx2, osteopontin, and ALP of adiposederived mesenchymal stem cells were significantly increased when cultured on functionalized PLGA/ HA microspheres coated with pDA. The introduction of HA nanoparticles is of great significance for the design and preparation of biodegradable PLGA microcarriers. The addition of HA to PLGA could also improve the stability of PLGA degradation and provide a certain mechanical strength [56]. Firstly, due to the improved surface roughness, addition of HA increases protein adsorption and cell proliferation. Secondly, surface pre-modification of microcarriers provides an optimization method for the immobilization of growth factor. Moreover, HA partially neutralized the local low $\mathrm{pH}$ value caused by degradation of PLGA microspheres, which reduced the effect on the structural integrity of the transferred IGF-1 [57, 58]. For PLGA microspheres, the selection of synthetic methods, particle size control and surface modification can increase the adsorption of insulin and IGF-1, optimize their release kinetics, and increase cell adhesion to achieve better osteogenic effect.

\section{HA}

As the main component of natural bone, HA is widely used in orthopedics and dentistry to promote osteogenesis. The advantage of $\mathrm{HA}$ in bone is attributed to its structure and function similar to the mineral composition in bones and teeth. Due to its nano-structure characteristics and chemical affinity to molecules, ions and metal, HA is considered as a delivery system for peptides, proteins, antibiotics, drugs, and genes [59].

Insulin delivery system based on HA nanospheres has been widely used in blood glucose regulation [60-62]. Some studies have found that adding insulin to HA can enhance the effect of HA on osteogenesis [63, 64]. Lasgorceix et al. [65] studied the effects of HA and Si substituted HA granules loaded with insulin on osteoblasts, but no obvious cell proliferation was observed. Scudeller et al. [66] studied the adsorption effect of HA on insulin. In this study, strontium (SrHA) and zinc (ZnHA) were used on the surface to replace $\mathrm{Ca}^{2+}$ in HA. Results showed that the modification of zinc increased the surface area of HA microspheres and enhanced insulin adsorption capacity of HA microspheres. However, in vitro cell culture revealed that insulin-loaded SrHA promoted stromal cell proliferation, whereas insulin-loaded HA and ZnHA had no such effect, which was related to the fact that the substitution of strontium did not affect the structure of a helix of insulin (Figure 4). In the delivery of insulin microspheres, HA is not easy to degrade, although have good mechanical strength, but not as good as gel polymer microspheres research widely, but in other studies, while testing different method for synthesis of microspheres osteogenesis effect, but no attention to the influence of insulin microspheres osteogenesis effect is due to the structure change of the insulin.

\section{Nanoparticles-hydrogel hybrid systems}

Hydrogels have a wide range of applications from tissue engineering to drug delivery. Loading nanoparticles to produce composite hydrogels that can be used to customize and extend the mechanical properties of materials has been greatly developed. Nanoparticles have offered a unique set of properties 
for drug delivery including high drug loading capacity, combinatorial delivery, controlled and sustained drug release, prolonged stability and lifetime, and targeted delivery. To further enhance therapeutic index, especially for localized application, nanoparticles have been increasingly combined with hydrogels to form a hybrid biomaterial system for controlled drug delivery.

\section{Gelatin}

Gelatin is a commonly used natural polymer, which is derived from collagen and can be used in under different conditions of alkalinity, acidity and neutrality. It can be applied to transfer plasmid DNA, protein and other biological activity factors, and protect them from loss of bioactivity [67]. Gelatin particles prepared by different methods have different degradation characteristics, which will affect the activity of the carried drugs. Moreover, gelatin easily dissolves rapidly in water, resulting in increased drug release. Nevertheless, use of a crosslinking agent is a major factor to maintain the stability of gelatin particles. Chemical crosslinking is a common solution, but the presence of residual crosslinkers may lead to toxic side effects [68].

Using gelatin and dextran and glycidyl methacrylate, Chen et al. [69] mixed dextran-glycidyl methacrylate/gelatin solution with polyethylene glycol aqueous solution to form gelatin microspheres, then IGF-1 was adsorbed by swelling method (Figure 5A). The particle size of the microspheres was mostly distributed in $30 \mu \mathrm{m}$. In vivo experiments of animals with periodontal defect, IGF-1 coated with gelatin particles was significantly more effective in bone formation than IGF-1 isolated in clot. The results showed that gelatin microspheres had a protective effect on IGF-1 and were used for drug delivery. Moreover, the use of dextran as a cross-linking agent can not only avoid the degradation of gelatin microspheres in IGF-1 solution, but also avoid the harmful effects caused by residues of chemical crosslinking agent.

To study cartilage repair by IGF-1-loaded nanoparticles, gelatin particles are also used to make hydrogel complexes of oligo(poly(ethylene glycol) fumarate) (OPF). Kim et al. [70] developed gelatin microparticles composite hydrogel particles by water oil method. After the adsorption of IGF-1, using glutaraldehyde crosslinking of macromolecule gel by double the hydrogel can be carried in cartilage repair two different kinds of growth factors, and the larger molecular weight reduce the density of gel, aperture, provide enough space for the cells to grow in, whether used alone or combined other growth factors, IGF-1 microspheres in the cartilage formation occupied the main role. The release of IGF-1 from OPF enhances the proliferation of MCF-7 cell lines and improves the growth of subchondral bone.

\section{Chitosan}

Chitosan is a kind of amino polysaccharide, which is obtained by alkaline N-deacetylation of natural macromolecule chitin [71]. Chitosan and its derivatives have multiple advantages, such as biodegradability, non-toxic, good adhesion, renewable resources, low cost, which have been commonly used in food, medicine and pharmaceutics field, especially in the development of nano-drug delivery system.

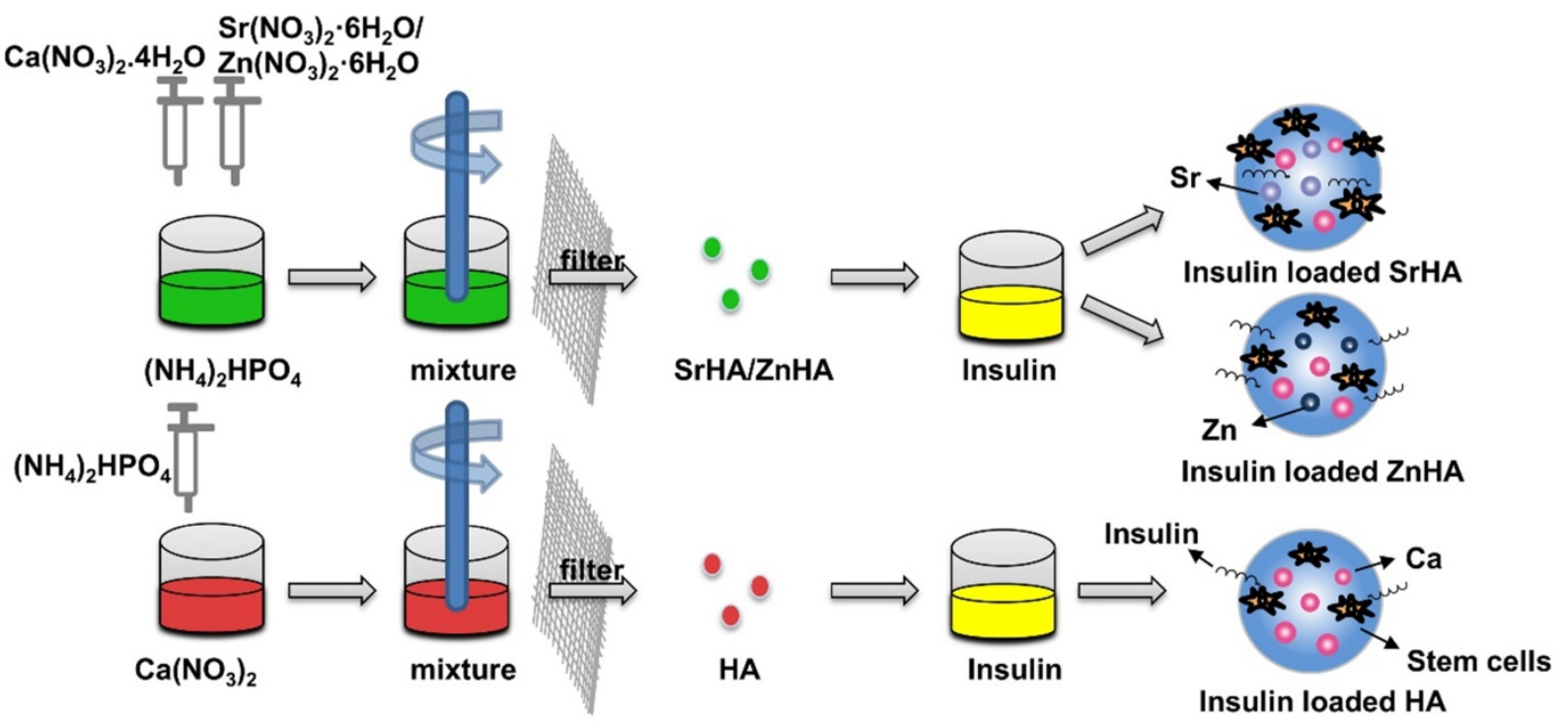

Figure 4. Insulin delivery system based on HA nanoparticles. Compared to the HA microspheres, the modification of zinc (ZnHA) enhance insulin adsorption capacity and strontium (SrHA) promotes stromal cell proliferation. 


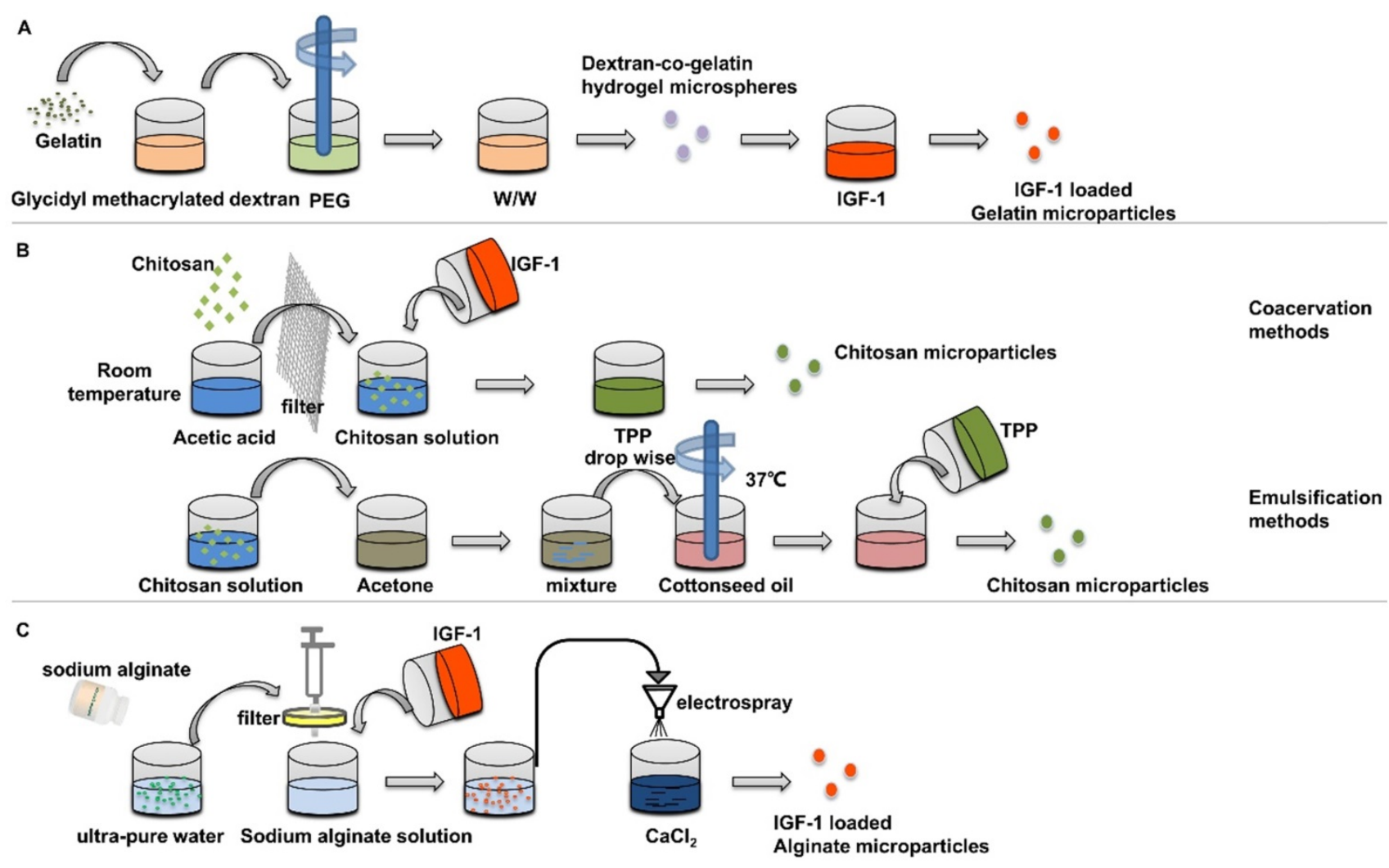

Figure 5. Preparation of insulin-loaded nanoparticles using gelatin, chitosan and alginate. (A) Gelatin Microspheres were prepared by an aqueous polyethylene glycol/dextran phase separation method. (B) Chitosan microparticles were prepared by emulsification and coacervation methods. (C) Insulin loaded alginate microparticles were prepared by electron spray method.

IGF-1 has been proved to promote the biomineralization on the surface of chitosan nanoparticles [72], and the use of porous chitosan scaffolds to adsorb IGF-1 can effectively promote the healing of bone defects [73]. Chitosan microspheres prepared under different conditions have different drug release rate. IGF-1-loaded chitosan microspheres can be prepared by emulsification and coacervation methods [74] (Figure 5B). The amount of IGF-1 encapsulated by coagulated particles is about $50 \%$ more than that encapsulated by emulsified particles. After 14 days, only 3.31\% of IGF-1 was released from the emulsified particles, while $30.68 \%$ from the coacervation particles, which indicated that organic solvents had adverse effects on the factors of the particles in the preparation process. In cell experiments, chitosan nanoparticles prepared by condensation method was cultured with osteoblasts. It was found that the nanoparticles enhanced the proliferation and differentiation of osteoblasts and increased the expression of osteogenic gene osterix.

When hydrogels with different components are used at the same time, a dual-transfer system with different factors can be obtained. Kim et al. [75] developed and characterized a chitosan gel/gelatin microspheres dual delivery system. The gelatin particles were prepared by water-in-oil emulsification, using glyoxal as a crosslinking agent to improve the stability of gelatin particles in a water environment. The obtained particles were encapsulated in chitosan solution to obtain chitosan/ gelatin particles, and nanoparticles of 50 to $100 \mu \mathrm{m}$ were further screened. The microspheres made of chitosan gel and gelatin can release bone morphogenetic protein-2 and IGF-1 in sequence, which can significantly improve the ALP activity of w-20-17 cells compared with that without microspheres. Synergistic growth factors can reduce the risk of overrelease of single factors and improve biosafety, but the optimal concentration and degradation properties of the factors carried by the dual delivery system have not been studied. Moreover, the above studies only demonstrated the promotion effect of osteogenesis mineralization at the cellular level, and the effect and toxicity level in vivo still need to be further evaluated.

\section{Alginate}

Alginate is a hydrophilic, biodegradable, natural polysaccharide with low toxicity that forms gel under gentle condition. Alginate possesses a variety of medical applications including cell encapsulation, drug stabilization and delivery [76, 77]. Shilpi Goswami [78] studied the alginate loaded with insulin 
and directly mixed it with alginate solution using calcium chloride as cross-linking agent. The particle size of the nanoparticles obtained was not uniform, 40-150 $\mathrm{nm}$. Moreover, it was found that when the amount of alginate added increased from $1 \mathrm{~g}$ to $2 \mathrm{~g}$, hemolytic increased and biosecurity decreased. After loading insulin with the swelling method, the release was observed to be close to $60 \%$ within $30 \mathrm{~min}$ and $100 \%$ within $5 \mathrm{~h}$. Duruel et al. [79] used electronic spraying method to prepare insulin-loaded alginate microparticles (Figure 5C). The average diameter of the spherical alginate particles was $296 \pm 18 \mu \mathrm{m}$. The encapsulation efficiency was $40 \%$, and the initial release rate was $60 \%$ in the first day. In this study, the longer release time was more appropriate for the slower cycle of osteogenesis. However, the author believes that in the sequential release, IGF-1 should be able to release continuously at the early stage, so alginate particles synthesized in calcium solution are a suitable choice. After ion exchange under other ions of microparticles in the medium, IGF-1 will be released by degradation of microspheres. Alginate particles and chitosan scaffolds were co-cultured with cementoblast cell line. The results showed that alginate particles containing IGF-1 promoted the expression of Runx2 compared with the control group containing chitosan alone.

\section{Y-PGA/ $\beta-T C P$}

$\gamma$-glutamic acid ( $\gamma$-PGA) has good expansibility and biocompatibility, and is suitable for clinical applications such as biogel, drug or gene delivery [80, 81]. Lin et al. [82] used a simple and mildly ionic gelation method to make a kind of nano particle composed of $\gamma$-PGA and chitosan, which can effectively reduce blood glucose level by loading insulin. To moderate pore size, hardness, and flexibly, $\gamma$-PGA is combined with $\beta$-tricalcium phosphate to obtain $\gamma$-PGA/TCP nanoparticles for tissue engineering [83, 84]. Shu et al. [85] prepared IGF-1 loaded $\mathrm{\gamma}$-PGA/TCP particles, and then demonstrated that the nanoparticles increase the proliferation of MC3T3-E1 cells and ALP activity (Figure 6).

Loading insulin into nanoparticles is a very important way to achieve desired insulin concentrations locally to improve the release time, but it is not enough to use nanoparticles alone in large area of bone defects, because it is difficult to maintain the morphology of defects. More research on osteogenesis is put into the combination of biological scaffolds and nano-microspheres. In the following section, we will highlight the strategy wherein nanoparticles are combined with scaffolds to improve the osteogenic effect and provide support for the defect.

\section{Scaffolds based insulin/IGF-1 delivery in bone regeneration}

Bone grafts can be classified into allografts bone, autograft bone, and artificial bone. Autograft is a "gold standard" for clinical treatment due to its excellent osteogenesis, osteoinduction, and osteoconduction [86], but this method is limited by the amount of bone supplied at the site of extraction and causes additional damage to the bone area of the donor. Allogeneic bone graft can avoid secondary injury in the donor bone area, but it has the potential risk of infections by viruses [87]. In recent years, artificial bone materials have become the focus of research on bone defect repair. Suitable artificial bone replacement materials should have the following conditions: (1) simulate the structure of natural bone, providing space for cell adhesion, angiogenesis and subsequent mineralization; (2) it has good supporting function; (3) appropriate degradation time to simulate the reconstruction of natural bone; (4) biocompatibility: immune behaviors such as rejection will not be induced; (5) promote osteogenic differentiation. Current studies include injectable hydrogel scaffolds, ceramic cement, polymer scaffolds, nanoparticle loaded scaffolds, etc.

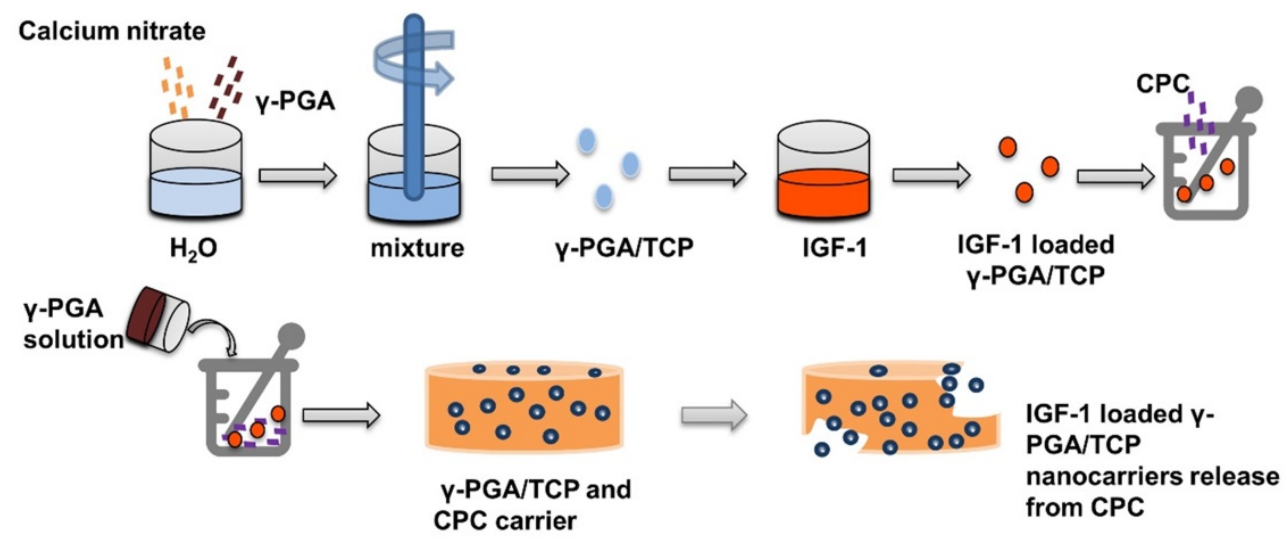

Figure 6. Insulin delivery system based on Y-PGA / TCP nanoparticles: Preparation and release of Y-PGA / TCP nanoparticles. 
HA is the component of bone, so its structure and hardness are the most similar to natural bone, but the brittleness of HA materials limits its application in bone tissue engineering $[88,89]$. And in the process of bone regeneration, it needs the continuous absorption of old tissue and the continuous mineralization of new tissue to carry out a functional reconstruction. Hydrogels are three-dimensional networks formed by hydrophilic homopolymers, copolymers or macromonomers. They swell in aqueous solution and provide an appropriate microenvironment similar to extracellular matrix, so as to promote the adhesion, migration, proliferation and differentiation of chondrocytes. Hydrogel can be implanted by minimally invasive injection and can form the desired shape to match irregular defects. Many natural materials such as chitosan, collagen or gelatin, alginate and hyaluronic acid can be used to prepare injectable hydrogels. Although hydrogels can adapt to different shapes of defects, their mechanical properties are relatively poor [90]. They cannot provide necessary support when promoting bone formation. Therefore, the improvement of their mechanical properties needs further study. The synergistic effect of different components in nano doped biological scaffolds can solve the defects caused by single materials [89]. Organo-silane and silk fibroin biopolymers can be assembled into multifunctional scaffolds. The incorporation of silk fibroin improves the porosity and mechanical elasticity of aerogel scaffolds, which can effectively support bone formation [91]. However, it is not enough only to have good structural characteristics, but also to induce bone formation. There is a close relationship between nano materials and bone regeneration, especially in four main aspects: (1)
Appropriate components in biomaterials can provide continuous nutrition for bone biomineralization [92]. (2) Nano/microspheres can carry appropriate growth factors and promote bone mineralization [93]. (3) Nano/microspheres combined with bone scaffolds can make up for the mechanical properties of bone scaffolds, such as adding PLGA microspheres to HA scaffolds [48]. (4) Nano microspheres can release the growth factors gradually with the process of osteogenesis, which is more suitable for the process of osteogenesis [94].

In bone tissue engineering, artificial materials used to repair defects are often in the form of scaffolds, among which HA has mechanical properties similar to those of natural bone. Hydrogel scaffolds are biocompatible and more plastic, but the scaffolds alone can only guide bone rather than induce bone regeneration. Insulin-loaded nanoparticles can improve the mechanical properties of bone scaffolds and release growth factors in a controlled manner, making up for the shortcomings of osteogenic scaffolds. Thus, a composite scaffold of insulin-loaded particles and porous scaffold may be a preferable strategy (Table 2).

Wang et al. [48] used the nano-hydroxyapatite/ collagen (nHAC) as the scaffold of insulin-loaded PLGA particles to repair the critical defect of rabbit mandible (Figure 7A). At 8 weeks, the new bone filled and mineralized the defect. nHAC/PLGA composite scaffolds have good mechanical and structural characteristics in the repair of large jaw defects, which can maintain the morphology of the defect site, promote cell adhesion on the scaffolds, and release insulin at a stable rate to promote the differentiation of osteoblasts.

Table 2. Insulin/IGF-1 composited scaffolds in bone regeneration

\begin{tabular}{|c|c|c|c|c|c|c|}
\hline Nanoparticles & Scaffold & Drug & Characterizations of scaffold & Release behaviour of scaffold & Effect in bone regeneration & Ref \\
\hline \multirow[t]{3}{*}{ PLGA } & \multirow[t]{3}{*}{ nHAC/PLGA } & Insulin & Nano-nHAC pore size: $127.4 \pm 21.1$ & $\begin{array}{l}\text { Initial burst release ( } 37 \% \text { within } 24 \mathrm{~h}) \text {; } \\
\text { Constant release within } 10 \text { days. }\end{array}$ & \multirow{3}{*}{$\begin{array}{l}\text { Enhance proliferation and } \\
\text { osteogenesis of BMSCs in vitro; } \\
\text { Restore critical Size bone defect in vivo. }\end{array}$} & \multirow[t]{3}{*}{ [48] } \\
\hline & & Insulin & $\begin{array}{l}\text { Micron-nHAC pore size: } 122.2 \pm 11.4 \\
\mu \mathrm{m}\end{array}$ & $\begin{array}{l}\text { Initial burst release ( } 23 \% \text { within } 24 \mathrm{~h} \text { ); } \\
\text { Sustained release over the next } 30 \text { days. }\end{array}$ & & \\
\hline & & Insulin & $\begin{array}{l}\text { 10×Micron-nHAC pore size: } 97.2 \pm \\
20.9 \mu \mathrm{m}\end{array}$ & $\begin{array}{l}\text { Initial burst release ( } 16 \% \text { within } 24 \mathrm{~h} \text { ); } \\
\text { Sustained release over the next } 50 \text { days. }\end{array}$ & & \\
\hline Gelatin & Dex-GMA/Gelatin & IGF-1 & $\begin{array}{l}\text { Loading } 5 \text { ng IGF-1 per mg of } \\
\text { freeze-dried scaffold }\end{array}$ & Sustained release during 28 days. & $\begin{array}{l}\text { Promoting the proliferation, } \\
\text { metabolism and ALP activity of } \\
\text { periodic metabolism fibroblasts. }\end{array}$ & [97] \\
\hline Gelatin & OPF & IGF-1 & $\begin{array}{l}\text { Degradation: remained stable over } 28 \\
\text { days in PBS; started to increase after } 7 \\
\text { days in collagenase-PBS }\end{array}$ & $\begin{array}{l}\text { Initial released ( } 36.6 \pm 8.8 \%, 4 \text { days) } \\
\text { Sustained release during } 28 \text { days. }\end{array}$ & $\begin{array}{l}\text { Enhance cartilage morphology in an } \\
\text { osteochondral defect. }\end{array}$ & [70] \\
\hline Chitosan & Chitosan & Insulin & $\begin{array}{l}\text { Scaffolds with 3-mm-height and } \\
\text { 5-mm-diameter cylindrical shape }\end{array}$ & $\begin{array}{l}5 \% \text { insulin initial released: }(40 \% \text {, the first } \\
4 \text { days); } \\
85 \% \text { insulin was sustained at } 28 \text { days. }\end{array}$ & $\begin{array}{l}\text { Enhance cartilage morphology and the } \\
\text { cartilaginous genes Sox-9. }\end{array}$ & [98] \\
\hline $\begin{array}{l}\text { Alginate/ } \\
\text { PLGA }\end{array}$ & Chitosan & IGF-1 & $\begin{array}{l}\text { Pore size: } 30-150 \mu \mathrm{m} \\
\text { Porosity of the scaffold: } 80 \%\end{array}$ & - & $\begin{array}{l}\text { Increased ECM synthesis, cell } \\
\text { differentiation and mineralize nodule } \\
\text { formation. }\end{array}$ & [79] \\
\hline
\end{tabular}

ALP: alkaline phosphatase; BMSCs: bone marrow derived mesenchymal stromal cells; Dex-GMA: dextran-glycidyl methacrylate; ECM: extracellular matrix; IGF-1: insulin-like growth factor 1; nHAC: nano-hydroxyapatite/collagen; OPF: oligo(poly(ethylene glycol) fumarate); PBS: phosphate buffered saline; PLGA: poly (lactic-co-glycolic acid) 
A

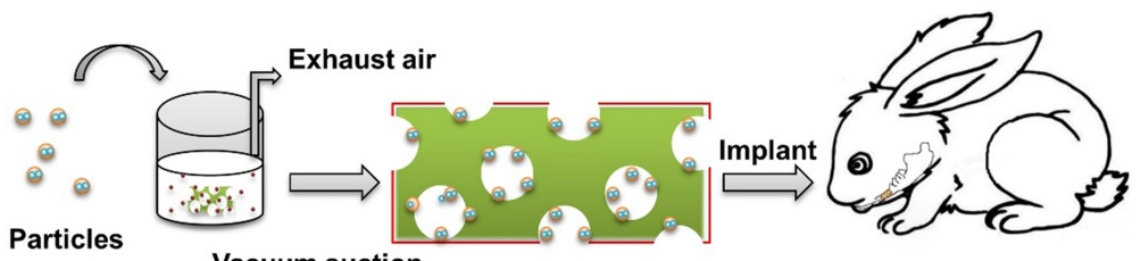

Vacuum suction

Microspheres in HAC Rabbit critical-size mandible defect

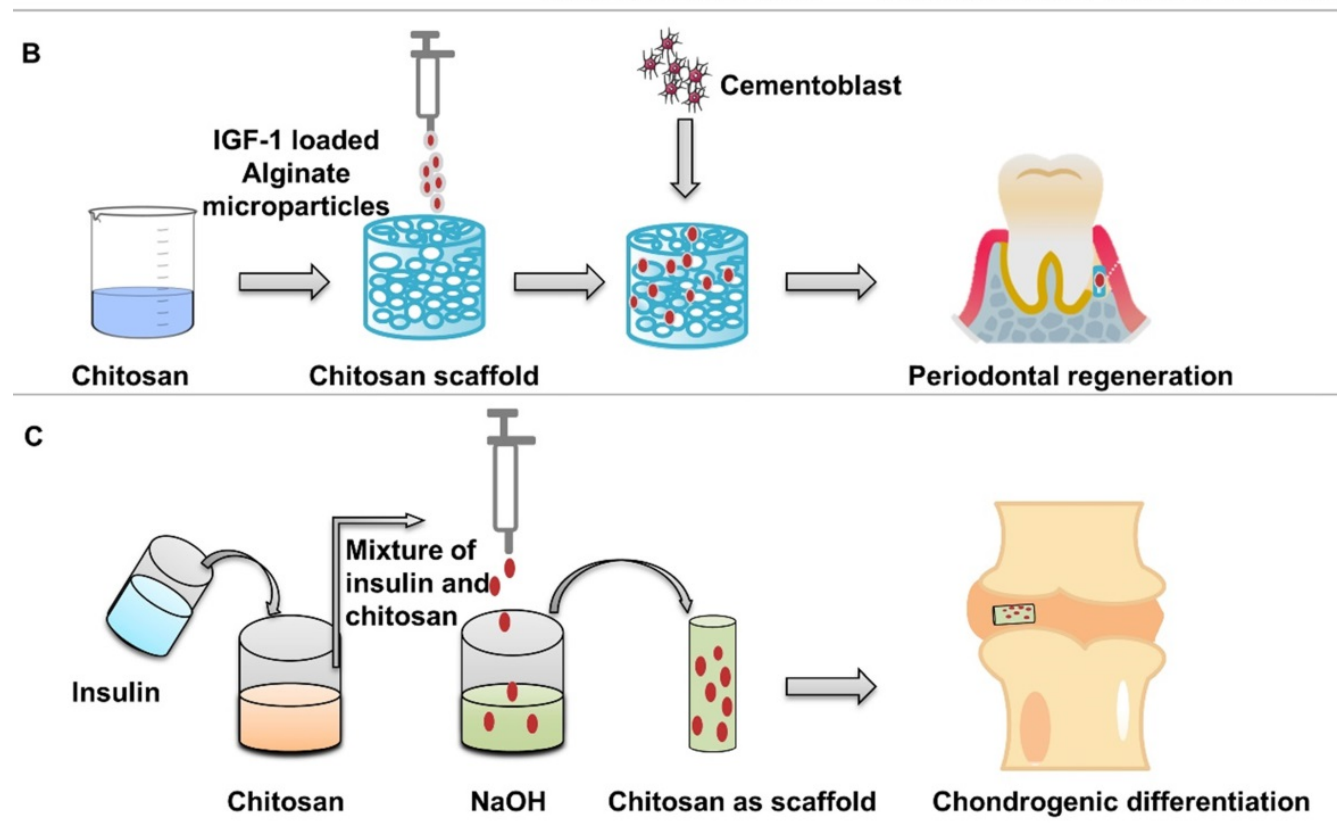

Figure 7. Preparation of insulin-loaded composite scaffold. (A) Composite scaffold was prepared using insulin-loaded PLGA microspheres and nHAC scaffolds. Adapted with permission from [48], copyright 2017, American Chemical Society. (B) Composite scaffold was prepared using IGF-1 loaded alginate microspheres and chitosan scaffolds. (C) Preparation of insulin-loaded chitosan scaffold.

The prepared nano-microspheres were placed in a polymer solution, and then the mixture was placed in the mold and dried to form a scaffold with a specific shape to carry the microspheres. As a carrier of growth factor, gelatin particles can be deposited in the hydrogel to form a solid with fixed shape, which can provide the release of IGF-1 under the action of collagenase [95]. The scaffolds synthesized by this method do not require high temperatures [96], but the crosslinking agents may be harmful to organisms. Chen et al. [97] used IGF-1 loaded dextran-glycidyl methacrylate/gelatin composite hydrogel scaffolds instead of single microspheres to obtain more non-toxic composite scaffolds. Suspended particulate matter in OPF can be used to obtain integral scaffolds by crosslinking agent without high temperature, and avoid the decrease in activity caused by thermal denaturation of bioactive factors [70]. This method has short crosslinking time, and is easy to obtain bilayer scaffolds.

Duruel et al. [79] prepared chitosan scaffolds by freeze-drying method. The internal connection porosity of the scaffold was $80 \%$. Sodium alginate particles loaded with IGF-1 were integrated into the scaffold structure, which induced the proliferation and differentiation of osteoblasts (Figure 7B). Malafaya et al. [98] used insulin-loaded chitosan particles to directly form scaffolds by drying method. Insulin solution and chitosan polymer were mixed, and then dripped into $\mathrm{NaOH}$ by a syringe to obtain insulin-loaded chitosan particles (Figure 7C). Then the chitosan particles were placed in the mold and dried at $60{ }^{\circ} \mathrm{C}$ to obtain a scaffold with a specific morphology formed by the materials of the particles. Chitosan scaffolds release insulin in a dose-dependent manner to support the adhesion and differentiation of chondrocytes and the biosynthesis of cartilage matrix. The encapsulation efficiency of insulin was $87.23 \%$. When the insulin loadings were $5 \%$, the release of chitosan particles was relatively stable.

nHAC scaffolds have high strength and are suitable for the repair of hard bone defects. The hydrogel was mixed with nanoparticles, the scaffolds with a more uniform distribution of nanoparticles were obtained by direct solidification. The degradation of hydrogel scaffolds is more suitable for the simultaneous existence of cartilage defects. Moreover, it is easy to get the desired shape and can obtain double-layer scaffolds with different growth factors. 


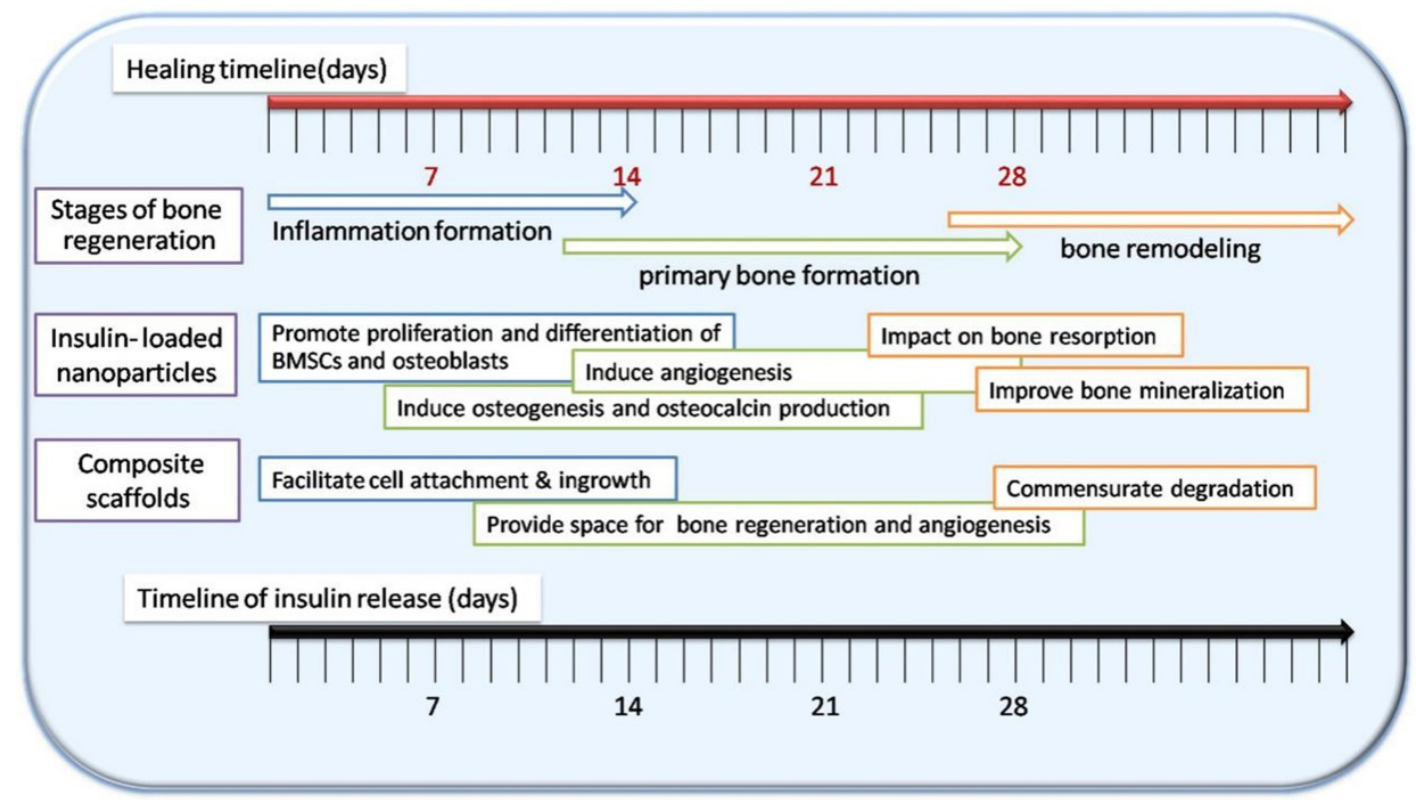

Figure 8. Phases of bone regeneration and the capacity of insulin-loaded nHAC/PLGA composite scaffolds. Adapted with permission from [48], copyright 2017, American Chemical Society.

\section{Conclusion and perspectives}

To summarize, insulin and IGF-1 have been increasingly recognized as an inducible factor for osteogenesis and angiogenesis, which is expected to be a preferable drug for bone regeneration. Nanoparticles have been widely studied in sustained release, which can provide opportunities for regulating local insulin concentration and have great potential in bone regeneration (Figure 8). This review presents the latest advances of insulin-loaded nanoparticles, including PLGA, HA, gelatin, chitosan, alginate, and $\gamma$-PGA/ $\beta$-TCP. Information on nanocarriers introduced in this review is summarized in Table 1. Information on scaffold introduced in this review is summarized in Table 2 . It is important to note that there remain challenges to be fulfilled. For example, the loading efficiency remains to be improved. In addition, the use of insulin-loaded nanoparticles alone is difficult to provide support and repair of large-scale defects. Strategies to combine insulin carrying nanoparticles and scaffolds are needed. In order to control insulin release at the optimal time, a lot of improvements are undergoing.

In conclusion, bone regeneration is a long-term and complex process, and local delivery of insulin with various strategies would certainly promote the process, and produce beneficial effects in bone regeneration.

\section{Abbreviations}

ALP: alkaline phosphatase; Cxc19: chemokine (C-X-C motif) ligand 9; ERK1/2: extracellular signal-related kinases; HA: hydroxyapatite; IGF: insulin and insulin-like growth factor; IGF-1: Insulin-like growth factor 1; IGFBPs: insulin like growth factor binding proteins; IR: insulin receptors; IRS: insulin receptor substrate; MAPK: mitogen activated protein kinase; mTORC1: rapamycin complex 1; nHAC: nano-hydroxyapatite/collagen; OPF: oligo(poly(ethylene glycol) fumarate); pDA: polydopamine; PI3-K: phosphoinositide-3-kinase; PLGA: poly (lactic-co-glycolic acid); RANKL: activator of nuclear factor kappa $B$; $\gamma$-PGA/ $\beta$-TCP: ( $\gamma$-glutamic acid)/ $\beta$-tricalcium phosphate; Run $\times 2$ : runt-related transcription factor 2; SrHA: strontium substitution in hydroxyapatite; ZnHA: zinc substitution in hydroxyapatite.

\section{Acknowledgements}

This work was supported by National Natural Science Foundation of China (81801004), Shanxi Province Key Research and Development Program (201903D321148), Scientific and Technological Innovation Programs of Higher Education Institutions in Shanxi (2019L0438, 2020L0209), Graduate Education Innovation Project of Shanxi Province (2019SY278, 2020SY243) and Shanxi Medical University School and Hospital of Stomatology (KY201901, KY201906).

\section{Competing Interests}

The authors have declared that no competing interest exists. 


\section{References}

1. Lobb DC, DeGeorge BR Jr, Chhabra AB. Bone graft substitutes: current concepts and future expectations. J Hand Surg Am. 2019; 44: 497-505.e2.

2. Winkler T, Sass FA, Duda GN, Schmidt-Bleek K. A review of biomaterials in bone defect healing, remaining shortcomings and future opportunities for bone tissue engineering: the unsolved challenge. Bone Joint Res. 2018; 7: 232-43

3. Habraken W, Habibovic P, Epple M, Bohner M. Calcium phosphates in biomedical applications: materials for the future? Materials Today. 2016; 19: 69-87.

4. Rauch F, Glorieux FH. Osteogenesis imperfecta. Lancet. 2004; 363: 1377-85.

5. Scott DL, Wolfe F, Huizinga TW. Rheumatoid arthritis. Lancet. 2010; 376: 1094-108.

6. Graham ML, Schuurman HJ. Validity of animal models of type 1 diabetes, and strategies to enhance their utility in translational research. Eur J Pharmacol. 2015; 759: 221-30.

7. Maratova K, Soucek O, Matyskova J, Hlavka Z, Petruzelkova L, Obermannova $B$, et al. Muscle functions and bone strength are impaired in adolescents with type 1 diabetes. Bone. 2018; 106: 22-7.

8. Nordklint AK, Almdal TP, Vestergaard P, Lundby-Christensen L, Jørgensen NR, Boesgaard TW, et al. Effect of metformin vs. placebo in combination with insulin analogues on bone markers P1NP and CTX in patients with type 2 diabetes mellitus. Calcif Tissue Int. 2020; 107: 160-9.

9. Vestergaard P, Rejnmark L, Mosekilde L. Relative fracture risk in patients with diabetes mellitus, and the impact of insulin and oral antidiabetic medication on relative fracture risk. Diabetologia. 2005; 48: 1292-9.

10. Hynes B, Kumar AH, O'Sullivan J, Klein Buneker C, Leblond AL, Weiss S, et al. Potent endothelial progenitor cell-conditioned media-related antiapoptotic, cardiotrophic, and pro-angiogenic effects post-myocardial infarction are mediated by insulin-like growth factor-1. Eur Heart J. 2013; 34: 782-9.

11. Paglia DN, Wey A, Breitbart EA, Faiwiszewski J, Mehta SK, Al-Zube L, et al. Effects of local insulin delivery on subperiosteal angiogenesis and mineralized tissue formation during fracture healing. J Orthop Res. 2013; 31: 783-91.

12. Rabinovsky ED, Draghia-Akli R. Insulin-like growth factor I plasmid therapy promotes in vivo angiogenesis. Mol Ther. 2004; 9: 46-55.

13. Cornish J, Callon KE, Reid IR. Insulin increases histomorphometric indices of bone formation in vivo. Calcif Tissue Int. 1996; 59: 492-5.

14. Thomas DM, Udagawa N, Hards DK, Quinn JM, Moseley JM, Findlay DM, et al. Insulin receptor expression in primary and cultured osteoclast-like cells. Bone. 1998; 23: 181-6

15. Xian L, Wu X, Pang L, Lou M, Rosen CJ, Qiu T, et al. Matrix IGF-1 maintains bone mass by activation of mTOR in mesenchymal stem cells. Nat Med. 2012; 18: 1095-101.

16. Guler HP, Zapf J, Schmid C, Froesch ER. Insulin-like growth factors I and II in healthy man. Estimations of half-lives and production rates. Acta Endocrinol (Copenh). 1989; 121: 753-8.

17. Duan $\mathrm{C}, \mathrm{Xu} \mathrm{Q}$. Roles of insulin-like growth factor (IGF) binding proteins in regulating IGF actions. Gen Comp Endocrinol. 2005; 142: 44-52.

18. Li H, Zhang Z, Bao X, Xu G, Yao P. Fatty acid and quaternary ammonium modified chitosan nanoparticles for insulin delivery. Colloids Surf B Biointerfaces. 2018; 170: 136-43

19. Ferron $M$, Wei J, Yoshizawa T, Del Fattore A, DePinho RA, Teti A, et al. Insulin signaling in osteoblasts integrates bone remodeling and energy metabolism. Cell. 2010; 142: 296-308

20. Fulzele K, Riddle RC, DiGirolamo DJ, Cao X, Wan C, Chen D, et al. Insulin receptor signaling in osteoblasts regulates postnatal bone acquisition and body composition. Cell. 2010; 142: 309-19.

21. Saltiel AR, Kahn CR. Insulin signalling and the regulation of glucose and lipid metabolism. Nature. 2001; 414: 799-806.

22. Yang J, Zhang X, Wang W, Liu J. Insulin stimulates osteoblast proliferation and differentiation through ERK and PI3K in MG-63 cells. Cell Biochem Funct. 2010; 28: 334-41.

23. Ogata N, Chikazu D, Kubota N, Terauchi Y, Tobe K, Azuma Y, et al. Insulin receptor substrate- 1 in osteoblast is indispensable for maintaining bone turnover. J Clin Invest. 2000; 105: 935-43.

24. Xuan NT, Hoang NH, Nhung VP, Duong NT, Ha NH, Hai NV. Regulation of dendritic cell function by insulin/IGF-1/PI3K/Akt signaling through klotho expression. J Recept Signal Transduct Res. 2017; 37: 297-303.

25. Denley A, Carroll JM, Brierley GV, Cosgrove L, Wallace J, Forbes B, et al. Differential activation of insulin receptor substrates 1 and 2 by insulin-like growth factor-activated insulin receptors. Mol Cell Biol. 2007; 27: 3569-77.

26. Lowenstein EJ, Daly RJ, Batzer AG, Li W, Margolis B, Lammers R, et al. The $\mathrm{SH} 2$ and $\mathrm{SH} 3$ domain-containing protein GRB2 links receptor tyrosine kinases to ras signaling. Cell. 1992; 70: 431-42.

27. Fritsche L, Neukamm SS, Lehmann R, Kremmer E, Hennige AM, HunderGugel A, et al. Insulin-induced serine phosphorylation of IRS-2 via ERK1/2 and mTOR: studies on the function of Ser675 and Ser907. Am J Physiol Endocrinol Metab. 2011; 300: E824-36.

28. Chen $\mathrm{H}$, Michel $\mathrm{T}$. Insulin signaling in vascular endothelial cells: a key role for heterotrimeric $\mathrm{G}$ proteins revealed by siRNA-mediated Gbeta1 knockdown. Biochemistry. 2006; 45: 8023-33.

29. Pramojanee SN, Phimphilai M, Chattipakorn N, Chattipakorn SC. Possible roles of insulin signaling in osteoblasts. Endocr Res. 2014; 39: 144-51.
30. Yoon H, Kim HL, Chun YS, Shin DH, Lee KH, Shin CS, et al. NAA10 controls osteoblast differentiation and bone formation as a feedback regulator of Runx2. Nat Commun. 2014; 5: 5176.

31. Fujita T, Azuma Y, Fukuyama R, Hattori Y, Yoshida C, Koida M, et al. Runx2 induces osteoblast and chondrocyte differentiation and enhances their migration by coupling with PI3K-Akt signaling. J Cell Biol. 2004; 166: 85-95.

32. Menon S, Dibble CC, Talbott G, Hoxhaj G, Valvezan AJ, Takahashi $H$, et al Spatial control of the TSC complex integrates insulin and nutrient regulation of mTORC1 at the lysosome. Cell. 2014; 156: 771-85.

33. Fukumoto S, Martin TJ. Bone as an endocrine organ. Trends Endocrinol Metab. 2009; 20: 230-6

34. Zigdon-Giladi H, Bick T, Morgan EF, Lewinson D, Machtei EE. Peripheral blood-derived endothelial progenitor cells enhance vertical bone formation. Clin Implant Dent Relat Res. 2015; 17: 83-92.

35. Fuchs S, Ghanaati S, Orth C, Barbeck M, Kolbe M, Hofmann A, et al. Contribution of outgrowth endothelial cells from human peripheral blood on in vivo vascularization of bone tissue engineered constructs based on starch polycaprolactone scaffolds. Biomaterials. 2009; 30: 526-34.

36. Sengupta A, Patel PA, Yuldasheva NY, Mughal RS, Galloway S, Viswambharan $\mathrm{H}$, et al. Endothelial insulin receptor restoration rescues vascular function in male insulin receptor haploinsufficient mice. Endocrinology. 2018; 159: 2917-25.

37. Chisalita SI, Arnqvist HJ. Insulin-like growth factor I receptors are more abundant than insulin receptors in human micro- and macrovascular endothelial cells. Am J Physiol Endocrinol Metab. 2004; 286: E896-901.

38. Tsuruzoe K, Emkey R, Kriauciunas KM, Ueki K, Kahn CR. Insulin receptor substrate 3 (IRS-3) and IRS-4 impair IRS-1- and IRS-2-mediated signaling. Mol Cell Biol. 2001; 21: 26-38.

39. LeRoith D, Werner H, Beitner-Johnson D, Roberts CT, Jr. Molecular and cellular aspects of the insulin-like growth factor I receptor. Endocr Rev. 1995; 16: 143-63.

40. Jacobo SM, Kazlauskas A. Insulin-like growth factor 1 (IGF-1) stabilizes nascent blood vessels. J Biol Chem. 2015; 290: 6349-60

41. Sukhanov S, Higashi Y, Shai SY, Vaughn C, Mohler J, Li Y, et al. IGF-1 reduces inflammatory responses, suppresses oxidative stress, and decreases atherosclerosis progression in ApoE-deficient mice. Arterioscler Thromb Vasc Biol. 2007; 27: 2684-90.

42. Huang B, Wang W, Li Q, Wang Z, Yan B, Zhang Z, et al. Osteoblasts secrete Cxcl9 to regulate angiogenesis in bone. Nat Commun. 2016; 7: 13885.

43. Ishida K, Matsumoto T, Sasaki K, Mifune Y, Tei K, Kubo S, et al. Bone regeneration properties of granulocyte colony-stimulating factor via neovascularization and osteogenesis. Tissue Eng Part A. 2010; 16: 3271-84.

44. Jose MV, Thomas V, Johnson KT, Dean DR, Nyairo E. Aligned PLGA/HA nanofibrous nanocomposite scaffolds for bone tissue engineering. Acta Biomater. 2009. 5: 305-15.

45. Mir M, Ahmed N, Rehman AU. Recent applications of PLGA based nanostructures in drug delivery. Colloids Surf B Biointerfaces. 2017; 159: 217-31.

46. Wang X, Qi F, Xing H, Zhang X, Lu C, Zheng J, et al. Uniform-sized insulinloaded PLGA microspheres for improved early-stage peri-implant bone regeneration. Drug Deliv. 2019; 26: 1178-90.

47. Wang F, Song YL, Li CX, Li DH, Zhang HP, Ma AJ, et al. Sustained release of insulin-like growth factor-1 from poly(lactide-co-glycolide) microspheres improves osseointegration of dental implants in type 2 diabetic rats. Eur J Pharmacol. 2010; 640: 226-32

48. Wang $X, W u$ X, Xing $H$, Zhang G, Shi $Q, E$, et al. Porous nanohydroxyapatite/collagen scaffolds loading insulin PLGA particles for restoration of critical size bone defect. ACS Appl Mater Interfaces. 2017; 9: 11380-91.

49. Zamani F, Amani-Tehran M, Latifi M, Shokrgozar MA. The influence of surface nanoroughness of electrospun PLGA nanofibrous scaffold on nerve cell adhesion and proliferation. J Mater Sci Mater Med. 2013; 24: 1551-60.

50. Wang X, Zhang G, Qi F, Cheng Y, Lu X, Wang L, et al. Enhanced bone regeneration using an insulin-loaded nano-hydroxyapatite/collagen/PLGA composite scaffold. Int J Nanomedicine. 2018; 13: 117-27.

51. Choi GH, Lee HJ, Lee SC. Titanium-adhesive polymer nanoparticles as a surface-releasing system of dual osteogenic growth factors. Macromol Biosci. 2014; 14: 496-507.

52. Ko E, Yang K, Shin J, Cho SW. Polydopamine-assisted osteoinductive peptide immobilization of polymer scaffolds for enhanced bone regeneration by human adipose-derived stem cells. Biomacromolecules. 2013; 14: 3202-13.

53. Lee H, Dellatore SM, Miller WM, Messersmith PB. Mussel-inspired surface chemistry for multifunctional coatings. Science. 2007; 318: 426-30.

54. Liu M, Zeng G, Wang K, Wan Q, Tao L, Zhang X, et al. Recent developments in polydopamine: an emerging soft matter for surface modification and biomedical applications. Nanoscale. 2016; 8: 16819-40.

55. Gao T, Zhang N, Wang Z, Wang Y, Liu Y, Ito Y, et al. Biodegradable microcarriers of poly(lactide-co-glycolide) and nano-hydroxyapatite decorated with IGF-1 via polydopamine coating for enhancing cell proliferation and osteogenic differentiation. Macromol Biosci. 2015; 15: $1070-80$

56. Naik A, Shepherd DV, Shepherd JH, Best SM, Cameron RE. The effect of the type of HA on the degradation of PLGA/HA composites. Mater Sci Eng C Mater Biol Appl. 2017; 70: 824-31. 
57. van de Weert $M$, Hennink WE, Jiskoot $W$. Protein instability in poly(lactic-co-glycolic acid) microparticles. Pharm Res. 2000; 17: 1159-67.

58. Ngiam M, Liao S, Patil AJ, Cheng Z, Chan CK, Ramakrishna S. The fabrication of nano-hydroxyapatite on PLGA and PLGA/collagen nanofibrous composite scaffolds and their effects in osteoblastic behavior for bone tissue engineering. Bone. 2009; 45: 4-16.

59. Simionescu BC, Drobota M, Timpu D, Vasiliu T, Constantinescu CA, Rebleanu $\mathrm{D}$, et al. Biopolymers/poly(epsilon-caprolactone)/polyethylenimine functionalized nano-hydroxyapatite hybrid cryogel: Synthesis, characterization and application in gene delivery. Mater Sci Eng C Mater Biol Appl. 2017; 81: 167-76.

60. Paul W, Nesamony J, Sharma CP. Delivery of insulin from hydroxyapatite ceramic microspheres: preliminary in vivo studies. J Biomed Mater Res. 2002; 61: 660-2.

61. Zhang Y, Zhang L, Ban Q, Li J, Li CH, Guan YQ. Preparation and characterization of hydroxyapatite nanoparticles carrying insulin and gallic acid for insulin oral delivery. Nanomedicine. 2018; 14: 353-64.

62. Yu W, Jiang G, Liu D, Li L, Tong Z, Yao J, et al. Transdermal delivery of insulin with bioceramic composite microneedles fabricated by gelatin and hydroxyapatite. Mater Sci Eng C Mater Biol Appl. 2017; 73: 425-8.

63. Nandi SK, Kundu B, Mukherjee J, Mahato A, Datta S, Balla VK. Converted marine coral hydroxyapatite implants with growth factors: in vivo bone regeneration. Mater Sci Eng C Mater Biol Appl. 2015; 49: 816-23.

64. Haider A, Gupta KC, Kang IK. PLGA/nHA hybrid nanofiber scaffold as a nanocargo carrier of insulin for accelerating bone tissue regeneration. Nanoscale Res Lett. 2014; 9: 314

65. Lasgorceix M, Costa AM, Mavropoulos E, Sader M, Calasans M, Tanaka MN, et al. In vitro and in vivo evaluation of silicated hydroxyapatite and impact of insulin adsorption. J Mater Sci Mater Med. 2014; 25: 2383-93.

66. Scudeller LA, Mavropoulos E, Tanaka MN, Costa AM, Braga CAC, Lopez EO, et al. Effects on insulin adsorption due to zinc and strontium substitution in hydroxyapatite. Mater Sci Eng C Mater Biol Appl. 2017; 79: 802-11.

67. Young S, Wong M, Tabata Y, Mikos AG. Gelatin as a delivery vehicle for the controlled release of bioactive molecules. J Control Release. 2005 109. 256-74.

68. Liang HC, Chang WH, Lin KJ, Sung HW. Genipin-crosslinked gelatin microspheres as a drug carrier for intramuscular administration: in vitro and in vivo studies. J Biomed Mater Res A. 2003; 65: 271-82.

69. Chen FM, Zhao YM, Wu H, Deng ZH, Wang QT, Zhou W, et al. Enhancement of periodontal tissue regeneration by locally controlled delivery of insulin-like growth factor-I from dextran-co-gelatin microspheres. J Control Release. 2006; 114: 209-22.

70. Kim K, Lam J, Lu S, Spicer PP, Lueckgen A, Tabata Y, et al. Osteochondral tissue regeneration using a bilayered composite hydrogel with modulating dual growth factor release kinetics in a rabbit model. J Control Release. 2013; 168: 166-78.

71. Madihally SV, Matthew HWT. Porous chitosan scaffolds for tissue engineering. Biomaterials. 1999; 20: 1133-42.

72. Jayasuriya AC, Kibbe S. Rapid biomineralization of chitosan microparticles to apply in bone regeneration. J Mater Sci Mater Med. 2010; 21: 393-8.

73. Nandi SK, Kundu B, Basu D. Protein growth factors loaded highly porous chitosan scaffold: a comparison of bone healing properties. Mater Sci Eng C Mater Biol Appl. 2013; 33: 1267-75.

74. Mantripragada VP, Jayasuriya AC. IGF-1 release kinetics from chitosan microparticles fabricated using environmentally benign conditions. Mater Sci Eng C Mater Biol Appl. 2014; 42: 506-16.

75. Kim S, Kang Y, Krueger CA, Sen M, Holcomb JB, Chen D, et al. Sequential delivery of BMP-2 and IGF-1 using a chitosan gel with gelatin microspheres enhances early osteoblastic differentiation. Acta Biomater. 2012; 8: 1768-77.

76. Larsen BE, Bjornstad J, Pettersen EO, Tonnesen HH, Melvik JE. Rheological characterization of an injectable alginate gel system. BMC Biotechnol. 2015; 15: 29.

77. Perteghella S, Martella E, de Girolamo L, Perucca Orfei C, Pierini M, Fumagalli $\mathrm{V}$, et al. Fabrication of innovative silk/alginate microcarriers for mesenchymal stem cell delivery and tissue regeneration. Int J Mol Sci. 2017; 18: 1829.

78. Goswami S, Bajpai J, Bajpai AK. Calcium alginate nanocarriers as possible vehicles for oral delivery of insulin. J Exp Nanosci. 2014; 9: 337-56.

79. Duruel T, Cakmak AS, Akman A, Nohutcu RM, Gumusderelioglu M. Sequential IGF-1 and BMP-6 releasing chitosan/alginate/PLGA hybrid scaffolds for periodontal regeneration. Int J Biol Macromol. 2017; 104: 232-41.

80. Cardoso AP, Goncalves RM, Antunes JC, Pinto ML, Pinto AT, Castro F, et al. An interferon-gamma-delivery system based on chitosan/poly(gammaglutamic acid) polyelectrolyte complexes modulates macrophage-derived stimulation of cancer cell invasion in vitro. Acta Biomater. 2015; 23: 157-71.

81. Yan S, Rao S, Zhu J, Wang Z, Zhang Y, Duan Y, et al. Nanoporous multilayer poly(L-glutamic acid)/chitosan microcapsules for drug delivery. Int J Pharm. 2012; 427: 443-51.

82. Lin Y-H, Mi F-L, Chen C-T, Chang W-C, Peng S-F, Liang H-F, et al. Preparation and characterization of nanoparticles shelled with chitosan for oral insulin delivery. Biomacromolecules. 2007; 8: 146-52.

83. Hsieh CY, Tsai SP, Wang DM, Chang YN, Hsieh HJ. Preparation of gammaPGA/chitosan composite tissue engineering matrices. Biomaterials. 2005; 26: $5617-23$

84. Shu $\mathrm{X}$, Shi Q, Feng J, Xie X, Chen $\mathrm{Y}$. Design and in vitro evaluation of novel $\mathrm{Y}$-PGA/hydroxyapatite nanocomposites for bone tissue engineering. J Mater Sci. $2014 ;$ 49: 7742-9.
85. Shu X, Feng J, Feng J, Huang X, Li L, Shi Q Combined delivery of bone morphogenetic protein-2 and insulin-like growth factor-1 from nano-poly (gamma-glutamic acid)/beta-tricalcium phosphate-based calcium phosphate cement and its effect on bone regeneration in vitro. J Biomater Appl. 2017; 32: $547-60$.

86. Teotia AK, Gupta A, Raina DB, Lidgren L, Kumar A. Gelatin-modified bone substitute with bioactive molecules enhance cellular interactions and bone regeneration. ACS Appl Mater Interfaces. 2016; 8: 10775-87.

87. Zimmermann G, Moghaddam A. Allograft bone matrix versus synthetic bone graft substitutes. Injury. 2011; 42 Suppl 2: S16-21.

88. Lei $\mathrm{Y}, \mathrm{Xu} \mathrm{Z}, \mathrm{Ke} \mathrm{Q}$, Yin $\mathrm{W}$, Chen $\mathrm{Y}$, Zhang $\mathrm{C}$, et al. Strontium hydroxyapatite/chitosan nanohybrid scaffolds with enhanced osteoinductivity for bone tissue engineering. Mater Sci Eng C Mater Biol Appl. 2017; 72: 134-42.

89. Ruixin L, Cheng X, Yingjie L, Hao L, Caihong S, Weihua S, et al. Degradation behavior and compatibility of micro, nanoHA/chitosan scaffolds with interconnected spherical macropores. Int J Biol Macromol. 2017; 103: 385-94.

90. Maher SA, Doty SB, Torzilli PA, Thornton S, Lowman AM, Thomas JD, et al. Nondegradable hydrogels for the treatment of focal cartilage defects. J Biomed Mater Res A. 2007; 83: 145-55.

91. Maleki H, Shahbazi MA, Montes S, Hosseini SH, Eskandari MR, Zaunschirm $\mathrm{S}$, et al. Mechanically strong silica-silk fibroin bioaerogel: a hybrid scaffold with ordered honeycomb micromorphology and multiscale porosity for bone regeneration. ACS Appl Mater Interfaces. 2019; 11: 17256-69.

92. Li Y, Liu C. Nanomaterial-based bone regeneration. Nanoscale. 2017; 9: 4862-74.

93. Wang B, Guo Y, Chen X, Zeng C, Hu Q, Yin W, et al. Nanoparticle-modified chitosan-agarose-gelatin scaffold for sustained release of SDF-1 and BMP-2. Int J Nanomedicine. 2018; 13: 7395-408.

94. Li L, Zhou G, Wang Y, Yang G, Ding S, Zhou S. Controlled dual delivery of BMP-2 and dexamethasone by nanoparticle-embedded electrospun nanofibers for the efficient repair of critical-sized rat calvarial defect. Biomaterials. 2015; 37: 218-29.

95. Holland TA, Tabata Y, Mikos AG. Dual growth factor delivery from degradable oligo(poly(ethylene glycol) fumarate) hydrogel scaffolds for cartilage tissue engineering. J Control Release. 2005; 101: 111-25.

96. Kinard LA, Kasper FK, Mikos AG. Synthesis of oligo(poly(ethylene glycol) fumarate). Nat Protoc. 2012; 7: 1219-27.

97. Chen FM, Chen R, Wang XJ, Sun $\mathrm{HH}, \mathrm{Wu} Z \mathrm{ZF}$. In vitro cellular responses to scaffolds containing two microencapulated growth factors. Biomaterials. 2009; 30: 5215-24

98. Malafaya PB, Oliveira JT, Reis RL. The effect of insulin-loaded chitosan particle-aggregated scaffolds in chondrogenic differentiation. Tissue Eng Part A. $2010 ; 16: 735-47$ 